\title{
An analysis of the surgical outcomes of laparoendoscopic single- site myomectomy and multi-port laparoscopic myomectomy
}

\author{
Shi-Fang Zhou, Hai-Yan Wang, Kun Wang \\ Department of Integrated Traditional Chinese and Western Medicine, Obstetrics and Gynecology Hospital Affiliated to Fudan University, Shanghai, \\ China \\ Contributions: (I) Conception and design: SF Zhou, HY Wang; (II) Administrative support: HY Wang; (III) Provision of study materials or patients: \\ SF Zhou, HY Wang; (IV) Collection and assembly of data: SF Zhou, K Wang; (V) Data analysis and interpretation: SF Zhou; (VI) Manuscript \\ writing: All authors; (VII) Final approval of manuscript: All authors. \\ Correspondence to: Professor Hai-Yan Wang. Obstetrics and Gynecology Hospital of Fudan University, No. 128, Shenyang Road, Shanghai 200090, \\ China. Email: haiyanwang2002@163.com.
}

\begin{abstract}
Background: This study sought to compare the surgical results of patients undergoing a laparoendoscopic single-site myomectomy (LESS-M) and a conventional laparoscopic myomectomy (CLM) at our hospital.

Methods: The basic data of 233 patients undergoing LESS-M and 233 patients undergoing CLM at the Obstetrics and Gynecology Hospital Affiliated to Fudan University were collected from January 2018 to January 2020, and the results of the operations were compared by evaluating a number of factors, including operation time, intraoperative bleeding, postoperative fever, and postoperative maximum body temperature.

Results: The operation times of the LESS-M and CLM groups were 83.9 \pm 33.4 and $75.2 \pm 26.7 \mathrm{~min}$, respectively; the difference between the groups was statistically significant. The surgical blood loss of the LESS-M group was $86.1 \pm 76.9 \mathrm{~mL}$, and that of the CLM group was $83.8 \pm 79.9 \mathrm{~mL}(\mathrm{P}>0.05)$. When the diameter of a fibroid was $\geq 8 \mathrm{~cm}$, a fibroid was located in the posterior wall or the number of fibroids was $\geq 4$, the operation time of the CLM group was shorter than that of the LESS-M group. When the diameter of a fibroid was $\geq 8 \mathrm{~cm}$, the blood loss of the CLM group was less than that of the LESS-M group.

Conclusions: LESS-M is safe and feasible. If the diameter of a fibroid is $\geq 8 \mathrm{~cm}$, the fibroid is located in the posterior wall, or the number of fibroids is $\geq 4$, the utility of single-port surgery should be carefully considered.
\end{abstract}

Keywords: Fibroids; single-site laparoscopy; laparoscopic myomectomy; retrospective studies

Submitted Mar 31, 2021. Accepted for publication May 19, 2021.

doi: 10.21037/atm-21-1862

View this article at: http://dx.doi.org/10.21037/atm-21-1862

\section{Introduction}

Uterine fibroids are extremely common benign neoplasms of the uterus and are especially common in women of reproductive age (1-3). Research has shown that $51 \%$ of premenopausal women receive a new diagnosis of fibroids (4). Pathological examinations of surgical specimens showed that the prevalence of fibroids is $77 \%$ (5). Uterine fibroids can induce menorrhagia, dysmenorrhea, pelvic compression, infertility, miscarriage, and other symptoms. Treatment plans for fibroids depend on the size, location, number, symptoms, age of the patient, and fertility requirements. Common treatment methods include surgery, interventional embolization, ultrasound ablation, and drug therapy. At present, myomectomy is still the most commonly used treatment. Compared to laparoscopy surgery, laparoscopic myomectomy has less bleeding, a quick recovery time post-surgery, better cosmesis, and less surgical complications $(6,7)$.

In November 2014, the United States Food and Drug Administration (FDA) issued a safety communication severely restricting the use of power morcellators during minimally invasive surgery for women with uterine 
Page 2 of 8

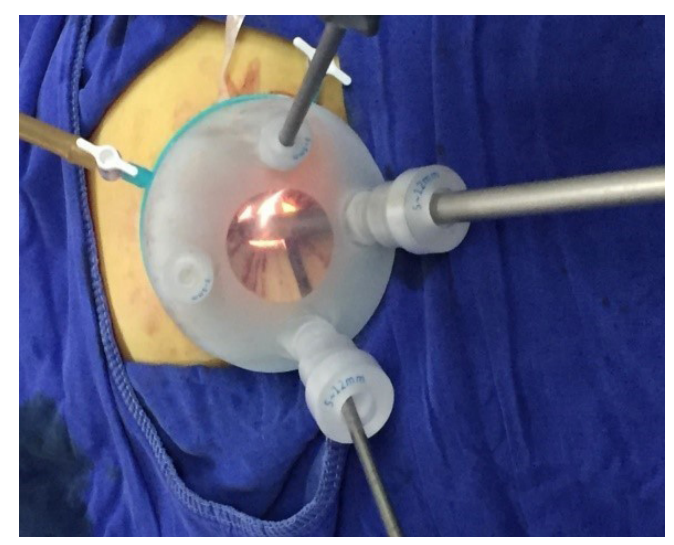

Figure 1 The 12-mm trocar was used for the $10-\mathrm{mm}$ flexible 3D laparoscope, and the other two 5-mm trocars were inserted into conventional laparoscopic instruments.

leiomyomas (8). Won et al. (9) found that the use of in-bag power morcellation in a laparoscopic myomectomy was feasible and safe. As the risks of open power morcellation are minimal, there was no change in the selection of myomectomy to treat leiomyoma after the FDA communication (10). However, many clinicians remain concerned that the fibroid morcellator can cause the intraabdominal dissemination of sarcoma, and the expansion of the right lower abdominal incision can cause subcutaneous hematoma, incision infection, abdominal scars and other adverse surgical outcomes. In recent years, clinical studies on the use of laparoendoscopic single-site myomectomy (LESS-M) to remove fibroids have been carried out abroad (11-15), and LESS-M is considered safe and reliable. To assess the exact feasibility and safety of LESS-M, we conducted a retrospective study to compare the surgical outcomes of LESS-M with those of conventional laparoscopic myomectomy (CLM).

We present the following article in accordance with the STROBE reporting checklist (available at http://dx.doi. org/10.21037/atm-21-1862).

\section{Methods}

\section{Subjects}

All procedures performed in this study involving human participants were in accordance with the Declaration of Helsinki (as revised in 2013). This study was approved by the Ethics Committee of the Obstetrics and Gynecology Hospital Affiliated to Fudan University (2019-07). Informed consent was obtained from all individual participants included in the study. Data were collected from the medical records of patients who underwent a LESS-M or a CLM from January 2018 to January 2020 at the Obstetrics and Gynecology Hospital Affiliated to Fudan University. In order to reduce bias and confounding variable, all the data of operations is treated by using Propensity Score Matching. Observational samples are matching by similar characteristics including age, number of births, operation history, and degree of intraoperative adhesion. A total of 466 patients who underwent LESS-M or CLM were included in the study; the LESS-M group comprised 233 patients, and the CLM group comprised 233 patients.

Patients were eligible to participate in the study if they met the following inclusion criteria: (I) underwent received laparoscopic surgery at our hospital; (II) had a pathological operation diagnosis of uterine leiomyoma; (III) the maximum diameter of their fibroids was $\leq 12 \mathrm{~cm}$; and (IV) the number of fibroids was $\leq 7$. Patients were excluded from the study if they had suspected or confirmed uterine malignant tumors (including endometrial or cervical lesions).

\section{Operation techniques}

For LESS-M, the skin of the umbilical orifice, the fascia layer and the peritoneum layer were cut medially at about $1.5 \mathrm{~cm}$. A wound retractor and a multichannel single port (Beijing Aerospace Kadi Technology Development Institute) were inserted through the umbilicus, and the airway was inflated to maintain a pneumoperitoneum pressure of $14 \mathrm{mmHg}$. A $12-\mathrm{mm}$ trocar was used for the $10-\mathrm{mm}$ flexible three-dimensional (3D) laparoscope, which was controlled by an assistant, and the other two 5 -mm trocars were inserted into conventional rigid laparoscopic instruments by the attending surgeon (see Figure 1). After irrigation with normal saline and the removal of any clots that had formed, the peritoneum, fascia, and subcutaneous tissue were then approximated and closed layer by layer using the 2-0 Polysorb suture (VICRYL, ETHICON); skin adhesive (Mepore) was used to close the skin incision (see Figure 2). With the exception of port placement and the method for myoma morcellation, the operative procedures of the CLM and LESS-M did not differ between the two groups. A $12-\mathrm{mm}$ trocar in the intraumbilical area and 3 ancillary 5 -mm trocars were placed in the parumbilical area and both lower lateral abdomens (see Figure 3). After the bleeding was completely stopped, the umbilical hole was sutured with absorbable thread (see Figure 4). 


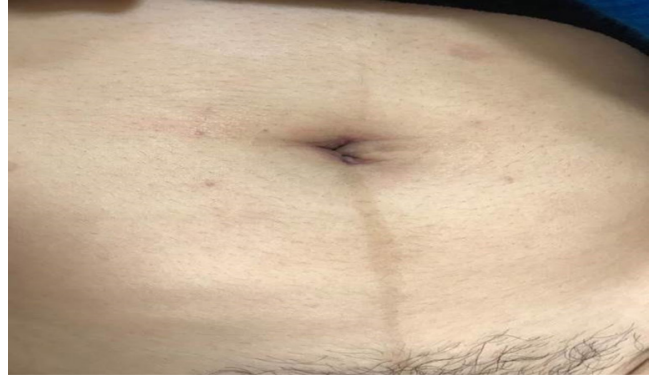

Figure 2 The peritoneum, fascia, subcutaneous tissues were closed layer by layer.

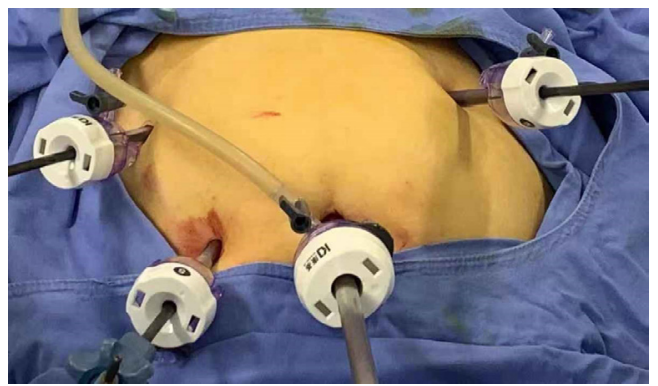

Figure 3 The 5-mm trocar was placed at the left and right Mai's point, and $5 \mathrm{~cm}$ to the left of the umbilicus; the $12 \mathrm{~mm}$ trocar was placed at the umbilical hole.

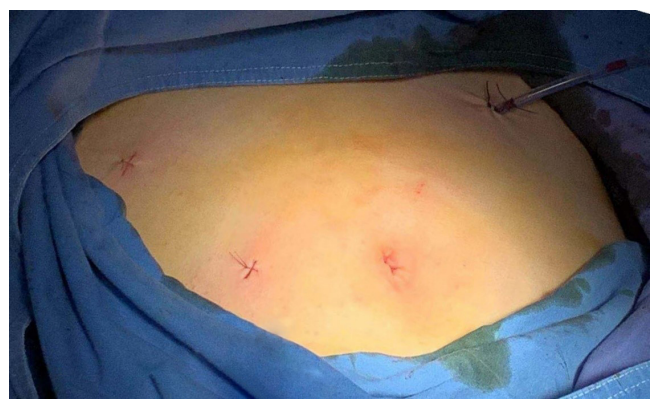

Figure 4 The closed abdomen at the end of the operation in CLM. CLM, conventional laparoscopic myomectomy.

\section{Observation index}

We collected patients' baseline data, including age, birth history, surgical history (e.g., appendix surgery or cesarean section), body mass index (BMI), maximum average diameter of fibroids, position of uterine fibroids (i.e., anterior, posterior, fundus, or sidewall), fibroid location (i.e., intermural or subserosal), and number of fibroids.
The main safety indicator was operation time. Total operation time was defined as the time interval from skin incision to suture completion. These safety indicators were bleeding volume, average hospital stay, postoperative maximum body temperature, exhaust time, surgical complications (intestinal injury, urinary tube injury, large blood vessel injury) and $24 \mathrm{~h}$ visual analogue scale (VAS). VAS scores were routinely recorded on the nursing record sheet. On the VAS, 0 represents no pain, 1 to 3 represents mild pain that does not affect sleep, 4 to 6 represents moderate pain, which affects sleep and requires the use of analgesics, and 7 to 10 represents severe pain, which seriously affects sleep. The amount of blood loss during surgery was calculated by the anesthesiologist. The length of hospital stay was defined as the time from the day of surgery to the day of discharge.

The laboratory indicator was the hemoglobin change value. The long-term surgical results evaluation indicator was patients' satisfaction with the surgical incision. We telephoned the patients and asked them to indicate their satisfaction on a 5 -point scale ranging from very dissatisfied to very satisfied (very dissatisfied $=1$, dissatisfied $=2$, generally satisfied $=3$, satisfied $=4$, and very satisfied $=5$ ).

We conducted a stratified analysis of the operation time and bleeding volume between the LESS-M and CLM groups according to the type of fibroid (i.e., intramural or subserosal), the number of fibroids (1, 2, 3, 4, and $\geq 5$ ), the location of the fibroid(s) (i.e., the anterior wall, posterior wall, lateral wall, or fundus of the uterus), and the diameter of the fibroid(s) $(<8$ and $\geq 8 \mathrm{~cm})$.

\section{Statistical method}

SPSS 25.0 was used for the statistical analysis. The continuous variables were compared using Student $t$-tests or Mann-Whitney $U$ tests. The categorical variables were compared using Chi-square or Fischer's exact tests. The results were considered statistically significant when the $\mathrm{P}$ values were $<0.05$.

\section{Results}

The study collected information on 233 LESS-M patients and 233 CLM patients. Table 1 sets out the results of the analysis of patients' basic data. There was no statistically significant differences between the two groups in terms of age, BMI, surgical history, and parity. The average diameter of the largest fibroids in the LESS-M group was 
Table 1 Baseline characteristics $(\bar{x} \pm s$, or $\mathrm{n})$

\begin{tabular}{|c|c|c|c|}
\hline Variable & $\begin{array}{l}\text { LESS-M } \\
(n=233)\end{array}$ & $\begin{array}{c}\text { CLM } \\
(n=233)\end{array}$ & $P$ \\
\hline Age (y) & $39.8 \pm 6.2$ & $40.0 \pm 6.6$ & 0.182 \\
\hline Parity (n) & 155 & 167 & 0.229 \\
\hline Surgery history (n) & 45 & 62 & 0.061 \\
\hline $\operatorname{BMI}\left(\mathrm{kg} / \mathrm{m}^{2}\right)$ & $22.1 \pm 1.9$ & $22.0 \pm 3.0$ & 0.518 \\
\hline Number of uterine fibroids ( $n$ ) & $1.7 \pm 1.1$ & $1.8 \pm 1.3$ & 0.366 \\
\hline Diameter of largest myoma (cm) & $6.8 \pm 1.7$ & $7.0 \pm 1.8$ & 0.654 \\
\hline Location of largest myoma & & & 0.158 \\
\hline Anterior & 104 & 102 & \\
\hline Posterior & 71 & 74 & \\
\hline Fundus & 45 & 33 & \\
\hline Lateral & 13 & 24 & \\
\hline Fibroid type & & & 0.065 \\
\hline Intermural & 161 & 159 & \\
\hline Subserosa & 72 & 74 & \\
\hline Number of fibroids & & & 0.456 \\
\hline 1 & 134 & 118 & \\
\hline 2 & 59 & 66 & \\
\hline 3 & 28 & 28 & \\
\hline$\geq 4$ & 12 & 19 & \\
\hline Number of fibroids $<8$ and $\geq 8 \mathrm{~cm}$ (n) & & & 0.842 \\
\hline$<8 \mathrm{~cm}$ & 161 & 159 & \\
\hline$\geq 8 \mathrm{~cm}$ & 72 & 74 & \\
\hline
\end{tabular}

LESS-M, laparoendoscopic single-site myomectomy; CLM, conventional laparoscopic myomectomy; BMI, body mass index.

Table 2 Intraoperative data $(\bar{x} \pm s$, or $\mathrm{n})$

\begin{tabular}{lccc}
\hline Variable & LESS-M $(\mathrm{n}=223)$ & CLM $(\mathrm{n}=223)$ & $P$ \\
\hline Total operative time $(\mathrm{min})$ & $83.9 \pm 33.4$ & $75.2 \pm 26.7$ & 0.002 \\
Blood loss $(\mathrm{mL})$ & $86.1 \pm 76.9$ & $83.8 \pm 79.9$ & 0.072 \\
Transfusion $(\mathrm{n})$ & 4 & 3 & 0.703 \\
Surgical complications & & & \\
Intestinal injury & 1 & 2 & \\
Urinary tube injury & 0 & 0 & \\
Large blood vessel injury & 0 & 0 & \\
\hline
\end{tabular}

LESS-M, laparoendoscopic single-site myomectomy; CLM, conventional laparoscopic myomectomy.
$6.8 \pm 1.7 \mathrm{~cm}$, and that of the CLM group was $7.0 \pm 1.8 \mathrm{~cm}$; the difference between the 2 groups was not statistically significant. The average number of fibroids in the LESS-M group was $1.7 \pm 1.1$, and that in the CLM group was $1.8 \pm 1.3$; the difference between the 2 groups was not statistically significant. The number of anterior wall fibroids in the LESS-M group was 104, the number of posterior wall fibroids was 71 , the number of fundus fibroids was 45 , and the number of lateral wall fibroids was 13 . The number of anterior wall fibroids in the CLM group was 102, and the number of posterior fibroids was 74 , the number of fundus fibroids was 33, and the number of lateral fibroids was 24 . There was no statistical difference between the 2 groups. The largest number of myomas in the LESS-M group was 161 intermural fibroids and 72 subserosal fibroids, while the largest number in the CLM group was 159 intramural fibroids, and 74 subserosal fibroids; there was no statistical difference between the two groups.

\section{Intraoperative data}

As Table 2 shows, the operation times of the LESS-M and CLM groups were $83.9 \pm 33.4$ and $75.2 \pm 26.7 \mathrm{~min}$, respectively; the difference between the groups was statistically significant. The surgical blood loss of the LESS-M group was $86.1 \pm 76.9 \mathrm{~mL}$, and that of the CLM group was $83.8 \pm 79.9 \mathrm{~mL}$; the difference between the 2 groups was not statistically significant. Four patients in the LESS-M group received blood transfusion due to extensive bleeding during the operation. There is no difference in postoperative complications between the two groups.

\section{Postoperative and follow-up data}

As Table 3 shows, the value of hemoglobin reduction in the LESS-M group was $10.5 \pm 6.1 \mathrm{~g} / \mathrm{L}$, and that of the CLM group was $12.2 \pm 8.9 \mathrm{~g} / \mathrm{L}$; the difference between the 2 groups was not statistically significant. The length of hospital stay in the LESS-M group was $4.9 \pm 1.6$ days, and that of the CLM group was $4.9 \pm 1.9$ days; the difference between the 2 groups was not statistically significant. The exhaust time of the LESS-M group was $30.4 \pm 12.7$ hours, and that of the CLM group was $29.7 \pm 12.9$ hours; the difference between the two groups was not statistically significant. The postoperative $24 \mathrm{~h}$ VAS score in the LESS-M group was $1.4 \pm 0.8$ points, and that in the CLM group was $1.5 \pm 0.6$ points; the difference between the 2 groups was not statistically significant. The satisfaction 
Table 3 Postoperative data $(\bar{x} \pm s$, or $\mathrm{n})$

\begin{tabular}{lccc}
\hline Variable & $\begin{array}{c}\text { LESS-M } \\
(\mathrm{n}=233)\end{array}$ & $\begin{array}{c}\text { CLM } \\
(\mathrm{n}=233)\end{array}$ & $\mathrm{P}$ \\
\hline $\begin{array}{l}\text { Maximum postoperative body } \\
\text { temperature }\left({ }^{\circ} \mathrm{C}\right)\end{array}$ & $37.6 \pm 0.3$ & $37.6 \pm 0.5$ & 0.866 \\
Length of hospital stay $(\mathrm{d})$ & $4.9 \pm 1.6$ & $4.9 \pm 1.9$ & 0.308 \\
Hemoglobin drop $(\mathrm{g} / \mathrm{dL})$ & $10.5 \pm 6.1$ & $12.2 \pm 8.9$ & 0.415 \\
Exhaust time $(\mathrm{h})$ & $30.4 \pm 12.7$ & $29.7 \pm 12.9$ & 0.236 \\
24 h VAS & $1.4 \pm 0.8$ & $1.5 \pm 0.6$ & 0.471 \\
Level of satisfaction & $4.4 \pm 0.8$ & $3.6 \pm 0.8$ & 0.022 \\
\hline
\end{tabular}

LESS-M, laparoendoscopic single-site myomectomy; CLM, conventional laparoscopic myomectomy; VAS, visual analogue scale.

Table 4 Analysis of differences in operation times $(\bar{x} \pm s$, or $\mathrm{n})$

\begin{tabular}{lcccc}
\hline Variable & Classification & LESS-M & CLM & $P$ \\
\hline Diameter of largest & $<8 \mathrm{~cm}$ & $74.0 \pm 25.9$ & $70.0 \pm 25.8$ & 0.358 \\
myoma & $\geq 8 \mathrm{~cm}$ & $97.0 \pm 37.2$ & $85.0 \pm 25.4$ & 0.033 \\
Location of largest & Anterior & $79.7 \pm 34.5$ & $74.4 \pm 23.6$ & 0.285 \\
myoma & Posterior & $83.9 \pm 30.0$ & $74.9 \pm 25.9$ & 0.021 \\
& Fundus & $92.9 \pm 40.0$ & $82.2 \pm 35.2$ & 0.271 \\
& Lateral & $76.4 \pm 26.1$ & $73.2 \pm 26.4$ & 0.626 \\
Number of fibroids & 1 & $78.6 \pm 29.4$ & $72.5 \pm 27.9$ & 0.090 \\
& 2 & $86.4 \pm 29.6$ & $76.8 \pm 25.6$ & 0.128 \\
& 3 & $84.3 \pm 36.3$ & $86.0 \pm 28.9$ & 0.496 \\
& $\geq 4$ & $130.1 \pm 50.7$ & $83.8 \pm 25.2$ & 0.000 \\
& Intermural & $85.4 \pm 34.4$ & $77.2 \pm 26.4$ & 0.127 \\
Fibroid type & Subserosa & $60.5 \pm 24.6$ & $57.5 \pm 24.4$ & 0.221 \\
\hline
\end{tabular}

LESS-M, laparoendoscopic single-site myomectomy; CLM, conventional laparoscopic myomectomy.

level of surgical incision in the LESS-M group was $4.4 \pm 0.8$, and that of patients in the CLM group was $3.6 \pm 0.8$; the difference between the 2 groups was statistically significant.

\section{Stratified analysis of the difference in operation times}

Table 4 sets out the data analysis results for the 2 groups. When the diameter of a fibroid was $<8 \mathrm{~cm}$, the average LESS-M operation time was $74.0 \pm 25.9 \mathrm{~min}$, and the average CLM operation time was $70.0 \pm 25.8 \mathrm{~min}$; the difference was
Table 5 Analysis of differences in operative blood loss $(\bar{x} \pm s$, or $\mathrm{n})$

\begin{tabular}{lcccc}
\hline Variable & Classification & LESS-M & CLM & $P$ \\
\hline Diameter of largest & $<8 \mathrm{~cm}$ & $79.8 \pm 75.8$ & $75.0 \pm 48.3$ & 0.172 \\
myoma & $\geq 8 \mathrm{~cm}$ & $113.1 \pm 74.9$ & $102.1 \pm 90.9$ & 0.001 \\
Location of largest & Anterior & $85.2 \pm 67.3$ & $80.9 \pm 68.0$ & 0.086 \\
myoma & Posterior & $89.0 \pm 84.2$ & $88.1 \pm 66.7$ & 0.820 \\
& Fundus & $84.4 \pm 80.7$ & $83.7 \pm 76.2$ & 0.919 \\
& Lateral & $90.4 \pm 100.3$ & $76.9 \pm 28.2$ & 0.404 \\
Number of fibroids & 1 & $81.7 \pm 76.3$ & $80.7 \pm 95.0$ & 0.133 \\
& 2 & $87.4 \pm 72.1$ & $83.3 \pm 42.0$ & 0.879 \\
& 3 & $89.9 \pm 93.3$ & $87.9 \pm 78.6$ & 0.162 \\
& $\geq 4$ & $90.0 \pm 35.3$ & $89.3 \pm 45.2$ & 0.659 \\
& Intermural & $87.8 \pm 78.4$ & $85.4 \pm 83.0$ & 0.139 \\
& Subserosa & $66.3 \pm 54.3$ & $64.3 \pm 38.0$ & 0.872 \\
\hline
\end{tabular}

LESS-M, laparoendoscopic single-site myomectomy; CLM, conventional laparoscopic myomectomy.

not statistically significant. Conversely, when the diameter of a fibroid was $\geq 8 \mathrm{~cm}$, the average LESS-M operation time was $97.0 \pm 37.2 \mathrm{~min}$, and the average CLM operation time was $85.0 \pm 25.4 \mathrm{~min}$; the difference was statistically significant $(\mathrm{P}=0.033)$. There was no statistical difference in the operation times of the anterior and lateral wall and fundus fibroids between the 2 groups. The average operation time of posterior fibroids in the LESS-M group was $83.9 \pm 30.0 \mathrm{~min}$, and that of the CLM group was $74.9 \pm 25.9 \mathrm{~min}$; the difference between the 2 groups was statistically significant $(\mathrm{P}=0.021)$. When the number of fibroids was $<4$, there was no statistically significant difference in the operation times between the 2 groups. However, when the number of fibroids was $\geq 4$, the average operation time of the LESS $M$ group was $130.1 \pm 50.7 \mathrm{~min}$, and that of the CLM group was $83.8 \pm 25.2 \mathrm{~min}$; the difference between the 2 groups was statistically significant.

\section{Stratified analysis of differences in the amount of bleeding}

Table 5 shows the results of the data analysis of the 2 groups of patients. When the diameter of a fibroid was $<8 \mathrm{~cm}$, the average bleeding volume of the LESS-M group was $79.8 \pm 75.8 \mathrm{~mL}$, and that of the CLM group was $75.0 \pm 48.3 \mathrm{~mL}$; the difference was not statistically significant. However, when the diameter of a fibroid was $\geq 8 \mathrm{~cm}$, the average bleeding volume of the LESS-M group 
was $113.1 \pm 74.9 \mathrm{~mL}$, and that of the CLM group was $102.1 \pm 90.9 \mathrm{~mL}$; the difference was statistically significant $(\mathrm{P}=0.001)$.

The difference in the operative blood loss of the anterior, posterior, lateral wall and fundus fibroids between the 2 groups was not statistically significant. Whether the number of fibroids was $<4$ or $\geq 4$, there was no statistical difference of blood loss between the 2 groups.

\section{Discussion}

In the past 10 years, LESS-M has developed rapidly, and studies have shown that LESS-M is safe and feasible (16-19). Park et al. (16) studied 515 cases of single-port laparoscopic gynecological surgeries, including total hysterectomies, adnexal surgeries, ovarian cystectomies, and salpingectomies. Of the 515 cases, only 17 cases of myomectomy were performed, and the operations were successful without surgical complications. However, it should be noted that Park et al. did not compare the advantages and disadvantages of LESS-M and multiport surgery. The LESS-M operation is difficult and the operation time is long. To date, only 8 clinical studies [comprising 2 randomized controlled trials $(13,20)$, and 6 cohort studies $(11,21-24)]$ have compared the results of LESS-M and CLM operations. The results of the 8 clinical studies all found evidence that LESS-M is safe and feasible, but the conclusions on total operation time, blood loss, postoperative hemoglobin reduction, and average hospital stay were inconsistent, and only 1 study analyzed morcellation time, suturing time, and removal time.

Choi et al. (23) found that operation time was less in the LESS-M group compared with the CLM group. Conversely, Han et al. (24) found that operation time was longer in the LESS-M group compared with the CLM group. Song et al. (13) found no difference in operation time, enucleation time, suturing time, and morcellation time. The present study found that LESS-M surgery takes longer than CLM surgery. Further, when the diameter of a fibroid is $\geq 8 \mathrm{~cm}$, or a fibroid is located in the posterior wall or the number of fibroids is $\geq 4$, the operation time of the CLM is shorter than that of the LESS-M. However, when the diameter of a fibroid is $<8 \mathrm{~cm}$, the number of fibroids is $<4$, or a fibroid is located on the anterior wall, lateral wall, or the fundus of the uterus, there is no statistical difference in the operation times between the 2 groups. Various studies have drawn different conclusions about the number of fibroids removed and the maximum diameter of fibroids. The inclusion criteria for Choi et al.'s (23) and Han et al.'s (24) studies were that the largest diameter be no more than $10 \mathrm{~cm}$ and the number of fibroids be less than 3 . Korean scholars believe that LESS-M is suitable for patients who have fibroids $\leq 5$ with a diameter $<12 \mathrm{~cm}$ (11). To choose an appropriate surgical approach, surgeons need to assess the location and size of each fibroid, patient fertility, and the risk of uterine rupture.

The inclusion criteria for the present study were that the largest diameter of a fibroid be $\leq 12 \mathrm{~cm}$, and the number of fibroids be $<7$. The operations were all successful. There were no differences in postoperative fever, postoperative hemoglobin changes, average hospital stay, or exhaust time between the 2 groups. In the process of the operations, the diameter and number of fibroids were related to the smooth completion of the operation, and the location of the fibroids also determined the difficulty of the operation. When the diameter of a fibroid was $\geq 8 \mathrm{~cm}$, the fibroid was located in the posterior wall or the number of fibroids was $\geq 4$, the operation time of the CLM group was better than that of LESS-M group. In terms of fibroid removal, anterior wall fibroids were easily removed; however, fibroids located in the lower uterine segment and in the deep uterine muscles were difficult to remove, as it was necessary to suspend the uterus or lift the uterus to assist the progress of the operation.

Operation time is related to the choice of surgical incision and suture time. Han et al. (24) used a transverse incision to cut the myometrium, while Song and Lee et al. $(13,21)$ used straight incisions. We elected to use a barbed suture to prevent tissue retraction and combined interlocking suturing with mattress suturing. Using a barbed suture to close uterus wall after laparoscopic myomectomy results in shorter operative times and less blood loss (25). Jeong et al. conducted 246 LESS-M operations using 2 suturing methods and compared the surgical outcomes. The result suggested that the interrupted suture method was more effective in relation to operating time and estimated blood loss than the continuous interlocking method (26).

The satisfaction level of surgical incision in the LESS-M group was $4.4 \pm 0.8$, and that of patients in the

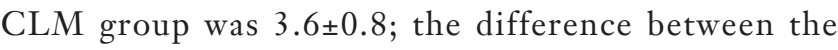
2 groups is statistically significant. Lee et al. (20) found that the observer scar assessment scale was lower in the LESS-M group than that of CLM after 1 week and 8 weeks from discharge. Several studies also have evaluated the cosmetic satisfaction of single port and multi-port laparoscopic surgery. For example, two prospective studies conducted abroad found that the cosmetic score 
of single-site laparoscopic hysterectomy was higher than that of traditional laparoscopy, indicating that single-site laparoscopy has outstanding cosmetic effects $(27,28)$.

The limitations of LESS-M cannot be ignored. First, the operation is difficult and there is a certain learning curve. The current study indicated that proficiency for LESS-M was achieved after about 45 operations (29). You et al. reported that surgeons need to operate on 20 patients to reach technical competency in hysterectomy (30). However, after achieving competency, surgeons conducting LESS-M operations can reach the same operation speed as that for CLM operations. Second, the port used in single-site laparoscopic surgery is expensive, which increases the cost of the surgery. Many scholars at home and abroad have reported that self-made ports, most of which are made of incision protective sleeves, medical gloves, and laparoscopic trocars, reduce the cost of medical consumables, enable more primary hospitals to carry out LESS-M, and have more benefits for patients. We also use improved lengthened instruments, such as lengthened needle holders. Barbed suture and self-fixing knot-free absorbable suture can also shorten the operation time and reduce the difficulty of suture (31). Finally, this study focused on the effects of surgery; however, there is still a lack of research on long-term recovery, especially in relation to reproduction. A prospective study should be conducted to collect large samples of clinical data and analyze the long-term safety and effectiveness of LESS-M.

\section{Acknowledgments}

Funding: None.

\section{Footnote}

Reporting Checklist: The authors have completed the STROBE reporting checklist. Available at http://dx.doi. org/10.21037/atm-21-1862

Data Sharing Statement: Available at http://dx.doi. org/10.21037/atm-21-1862

Conflicts of Interest: All authors have completed the ICMJE uniform disclosure form (available at http://dx.doi. org/10.21037/atm-21-1862). The authors have no conflicts of interest to declare.

Ethical Statement: The authors are accountable for all aspects of the work in ensuring that questions related to the accuracy or integrity of any part of the work are appropriately investigated and resolved. All procedures performed in this study involving human participants were in accordance with the Declaration of Helsinki (as revised in 2013). This study was approved by the Ethics Committee of the Obstetrics and Gynecology Hospital Affiliated to Fudan University (2019-07). Informed consent was obtained from all individual participants included in the study.

Open Access Statement: This is an Open Access article distributed in accordance with the Creative Commons Attribution-NonCommercial-NoDerivs 4.0 International License (CC BY-NC-ND 4.0), which permits the noncommercial replication and distribution of the article with the strict proviso that no changes or edits are made and the original work is properly cited (including links to both the formal publication through the relevant DOI and the license). See: https://creativecommons.org/licenses/by-nc-nd/4.0/.

\section{References}

1. Walker CL, Stewart EA. Uterine fibroids: the elephant in the room. Science 2005;308:1589-92.

2. Bulun SE. Uterine fibroids. $\mathrm{N}$ Engl J Med 2013;369:1344-55.

3. Kim JJ, Sefton EC. The role of progesterone signaling in the pathogenesis of uterine leiomyoma. Mol Cell Endocrinol 2012;358:223-31.

4. Marshall LM, Spiegelman D, Barbieri RL, et al. Variation in the incidence of uterine leiomyoma among premenopausal women by age and race. Obstet Gynecol 1997;90:967-73.

5. Cramer SF, Pathology A. The Frequency of Uterine Leiomyomas. Am J Clin Pathol 1990;94:435-8.

6. Yang W, Luo N, Ma L, et al. The Changes of Surgical Treatment for Symptomatic Uterine Myomas in the Past 15 Years. Gynecol Minim Invasive Ther 2018;7:10-5.

7. Bean EM, Cutner A, Holland T, et al. Laparoscopic Myomectomy: A Single-center Retrospective Review of 514 Patients. J Minim Invasive Gynecol 2017;24:485-93.

8. UPDATED laparoscopic uterine power morcellation in hysterectomy and myomectomy: FDA Safety Communication. Available online: http://www.fda.gov/ medicaldevices/safety/alertsandnotices/ucm424443.htm (Retrieved August 8, 2015).

9. Won YB, Lee HJ, Eoh KJ, et al. In-bag power morcellation technique in single-port laparoscopic myomectomy. Obstet Gynecol Sci 2018;61:267-73. 
10. Clark NM, Schembri M, Jacoby VL. Change in Surgical Practice for Women With Leiomyomas After the U.S. Food and Drug Administration Morcellator Safety Communication. Obstet Gynecol 2017;130:1057-63.

11. Kim SK, Lee JH, Lee JR, et al. Laparoendoscopic singlesite myomectomy versus conventional laparoscopic myomectomy: a comparison of surgical outcomes. J Minim Invasive Gynecol 2014;21:775-81.

12. Lee JH, Choi JS, Jeon SW, et al. A prospective comparison of single-port laparoscopically assisted vaginal hysterectomy using transumbilical GelPort access and multiport laparoscopically assisted vaginal hysterectomy. Eur J Obstet Gynecol Reprod Biol 2011;158:294-7.

13. Song T, Kim TJ, Lee SH, et al. Laparoendoscopic single-site myomectomy compared with conventional laparoscopic myomectomy: a multicenter, randomized, controlled trial. Fertil Steril 2015;104:1325-31.

14. Chen YJ, Wang PH, Ocampo EJ, et al. Single-port compared with conventional laparoscopic-assisted vaginal hysterectomy: a randomized controlled trial. Obstet Gynecol 2011;117:906-12.

15. Schmitt A, Crochet P, Knight S, et al. Single Port Laparoscopy Versus Conventional Laparoscopy in Benign Adnexal Diseases: a Systematic Review and Meta-Analysis. J Minim Invasive Gynecol 2017;24:1083-95.

16. Park JY, Kim TJ, Kang HJ, et al. Laparoendoscopic single site (LESS) surgery in benign gynecology: perioperative and late complications of 515 cases. Eur J Obstet Gynecol Reprod Biol 2013;167:215-8.

17. Fagotti A, Bottoni C, Vizzielli G, et al. Postoperative pain after conventional laparoscopy and laparoendoscopic single site surgery (LESS) for benign adnexal disease: a randomized trial. Fertil Steril 2011;96:255-9.e2.

18. Yim GW, Jung YW, Paek J, et al. Transumbilical singleport access versus conventional total laparoscopic hysterectomy: surgical outcomes. Am J Obstet Gynecol 2010;203:26.e1-6.

19. Kim TJ, Lee YY, Cha HH, et al. Single-port-access laparoscopic-assisted vaginal hysterectomy versus conventional laparoscopic-assisted vaginal hysterectomy: a comparison of perioperative outcomes. Surg Endosc 2010;24:2248-52.

20. Lee D, Kim SK, Kim K, et al. Advantages of Single-Port Laparoscopic Myomectomy Compared with Conventional Laparoscopic Myomectomy: A Randomized Controlled Study. J Minim Invasive Gynecol 2018;25:124-32.

21. Lee SW, Park EK, Lee SJ, et al. Comparison study of consecutive 100 cases of single port vs. multiport laparoscopic myomectomy; technical point of view. J Obstet Gynaecol 2017;37:616-21.

22. Kim SM, Baek JM, Park EK, et al. A Comparison of Single-, Two- and Three-Port Laparoscopic Myomectomy. JSLS 2015;19:e2015.00084.

23. Choi CH, Kim TH, Kim SH, et al. Surgical outcomes of a new approach to laparoscopic myomectomy: single-port and modified suture technique. J Minim Invasive Gynecol 2014;21:580-5.

24. Han CM, Lee CL, Su H, et al. Single-port laparoscopic myomectomy: initial operative experience and comparative outcome. Arch Gynecol Obstet 2013;287:295-300.

25. Chan CC, Lee CY. Feasibility and Safety of Absorbable Knotless Wound Closure Device in Laparoscopic Myomectomy. Biomed Res Int 2016;2016:2849476.

26. Jeong JH, Kim YR, Kim EJ, et al. Comparison of Surgical Outcomes according to Suturing Methods in Single Port Access Laparoscopic Myomectomy. J Menopausal Med 2015;21:47-55.

27. Song T, Cho J, Kim TJ, et al. Cosmetic outcomes of laparoendoscopic single-site hysterectomy compared with multi-port surgery: randomized controlled trial. J Minim Invasive Gynecol,2013;20:460-7.

28. Angioni S, Pontis A, Sedda F, et al. Single-port versus conventional multiport access prophylactic laparoscopic bilateral salpingo-oophorectomy in high-risk patients for ovarian cancer: a comparison of surgical outcomes. Onco Targets Ther 2015;8:1575-80.

29. Lee HJ, Kim JY, Kim SK, et al. Learning Curve Analysis and Surgical Outcomes of Single-port Laparoscopic Myomectomy. J Minim Invasive Gynecol 2015;22:607-11.

30. You SH, Huang CY, Su H, et al. The Power Law of Learning in Transumbilical Single-Port Laparoscopic Subtotal Hysterectomy. J Minim Invasive Gynecol 2018;25:994-1001.

31. Song T, Kim TJ, Kim WY, et al. Comparison of barbed suture versus traditional suture in laparoendoscopic singlesite myomectomy. Eur J Obstet Gynecol Reprod Biol 2015;185:99-102.

(English Language Editor: L. Huleatt)

Cite this article as: Zhou SF, Wang HY, Wang K. An analysis of the surgical outcomes of laparoendoscopic single-site myomectomy and multi-port laparoscopic myomectomy. Ann Transl Med 2021;9(11):927. doi: 10.21037/atm-21-1862 